http://dx.doi.org/10.4314/nit.v37i3.39

\title{
DEVELOPMENT OF BI-MODAL EXERCISE BICYCLE FOR PHYSICAL FITNESS AND REHABILITATION
}

\author{
O. P. Fidelis ${ }^{1,4,}{ }^{*}$, A. O. Falola ${ }^{2,4}$, D. 0. Odebiyi ${ }^{3}$ and E. O. Nwoye ${ }^{4}$ \\ 1, DEPT OF BIOMEDical TeCHNOLOGY, FEDERAL UNIVERSITY OF TECHNOLOGY, AKURE, ONDO STATE, NIGERIA \\ 2, BIOMEdicAL ENGINEERING SERVICES, LAgOS UNIVERSITY TEACHING HOSPITAL, IDI-ARABA, LAGOS STATE, NIGERIA \\ 3, DEPARTMENT OF PHYSIOTHERAPY, UNIVERSITY OF LAGOS, AKOKA, LAGOS STATE, NIGERIA \\ 4, DEPARTMENT OF BIOMEDICAL ENGINEERING, UNIVERSITY OF LAGOS, AKOKA, LAGOS STATE, NIGERIA \\ Email addresses.1opfidelis@futa.edu.ng, 2damolafalola@hotmail.com,3enwoye@unilag.edu.ng, \\ 4dodebiyi@unilag.edu.ng
}

\begin{abstract}
Exercise bicycles are used for kinesiological activities; to increase general fitness, and for training for cycling events. They are also used for weight loss. The aim of this study is to produce a special exercise bike which allows for both upper and lower limbs pedalling either independently or otherwise. The manufacturing processes employed in the design involved the use of AutoCAD design suite and other production engineering processes which included material selection and acquisition, cutting, welding and drilling. The device was tested for both comfort and effectiveness for cardiac rehabilitation using the rate of heartbeat as the test parameter. A strong positive correlation was found ( $p<0.001 ; r=0.962)$ between the two heart rate tests. An ergonomic evaluation of the bi-modal exercise bike showed 98\% suitability of the seat-pedal height with the knee height of the study population and $100 \%$ suitability of the seathandle post height with the buttock-knee length of the population. In conclusion, the goal of developing a bi-modal exercise bike that permits simultaneous upper and lower limbs pedalling was realised.
\end{abstract}

Keywords: exercise bicycle; cycling; ergometer; fitness; rehabilitation.

\section{INTRODUCTION}

Physical activities are beneficial for controlling body weight, reducing the chances of heart diseases, reducing the risk of diabetes and some other chronic diseases by improving the functions of the heart, lungs and improving the biomechanical system of the body [1]. Aside surgery and medication, several methods have been proposed for the prevention and treatment of heart conditions. One of such methods is the use of regulated and supervised exercise as therapy both for prevention of heart conditions and following medication or surgery [2].

Some of the significant benefits of exercise have been reported to include improved body mass index (BMI), improved insulin levels and fitness [3], improved conditions in type II diabetes [4], as well as cardiopulmonary and muscular strength [5] in people with spinal cord injury. Exercise has also been reported to reduce posttraumatic stress disorder [6].

A physical exercise is definitely beneficial to many people when it is performed intelligently and with proper medical guidance. Some of these benefits include reduction in the course of diseases, prevention of conditions such as obesity, diabetes, and hyperlipidaemia which are common causes of heart diseases. Exercise also lowers heart rate over time, increases maximal oxygen uptake $\left(\mathrm{VO}_{2 \max }\right)$ in the body, muscle strength, stroke volume and sub maximal working capacity. It helps in the restoration of normal functions in the case of cardiac rehabilitation, as well as the regulation of hormones [7-9].

The equipment used for fitness training and cardiac rehabilitation present many advantages for a cardiac patient and for healthy people who wish to avoid heart problems or wish to burn fat and loss weight [9]. One of such equipment is the exercise bicycle also called bicycle ergometer. Exercise bicycles are used for weight loss, to increase general fitness, and for training for cycle events [10]. There exist many types of exercise bicycles: those in recumbent positions, spinning machines - which are stationary bicycles built for spinning classes - standard ergometer and active

"Corresponding author, tel: +234-803-819-3799 
passive trainer [11]. These bikes come with different mechanisms for adjusting the resistance to the pedals, thus, adjusting the intensity of exercise.

Since cycling is similar to walking [12], it can serve as a rehabilitation technique for the restoration of walking ability in patients who are recovering from stroke [13]. These similarities exist in form of reciprocal flexion and extension movements of hip, knee, and ankle; and present alternating and coordinated antagonist muscle activation [11].

Pedalling an exercise bicycle is safe $[10,14,15]$ and convenient and can enhance muscular endurance [15]. Despite the similarity as walking, cycling has a superior range of motion (RoM) when compared to walking. Therefore, pedalling (during cycling) can help improve the functional range of motion of the lower limbs required in walking [16]. Cycling ensures that the trajectory of the feet can be restricted to a circle during performance and that the intensity of exercise can be altered by adjusting a few parameters on the cycling device without changing the course of the exercise [11]. As long as the training capacity of the patient can be adjusted to match their health status, physiologic response and rehabilitation evolution, cycling devices can perform a continuous and prolonged operation [17]. One unique feature of cycling is that it enhances exercise and training in persons who have one weak limb. In this case, the healthy limb helps the affected one through coupling of the pedals during the performance of the exercise. This encourages the use of the affected leg and the muscle control of the limbs, which may enable the affected leg to support more weight while standing [18]. The arm ergometer is also based on the principles used in cycle ergometry [10].

The main aim of the present study is to produce a dualnature exercise bicycle that permits the exercise of both the upper limbs and the lower limbs either independently or simultaneously. The design technically combines both the leg ergometer and the arm ergometer in one device. For physically fit persons, it will permit the training of both the lower and the upper limbs. It is also applicable in the rehabilitation of patients recovering from conditions such as stroke.

\section{MATERIALS AND METHOD}

\subsection{Materials for Design and Construction}

The major materials used for the construction of the exercise bicycle include:

1. Rectangular hollow iron (thickness $0.2 \mathrm{~cm}$ )

2. Cylindrical iron pipe $(\varnothing 4.7 \mathrm{~cm}$, thickness $0.1 \mathrm{~cm})$

3. Flywheel $(\varnothing 25.5 \mathrm{~cm})$

4. Pedals
5. Chain drives

6. Tension/ resistance cable

7. Cushion materials for the seat and handle bars Others are bolts \& nuts, pedal support, electrodes, coolant, grease, car paint, thinner and screws. Some instruments were also used especially in the test and evaluation processes. These include the metronome, a heart rate monitor, and an anthropometer.

\subsection{Design and Fabrication}

A flowchart of the manufacturing process for the exercise bicycle is shown in Figure 1. The steps are briefly discussed as follows:

1. Design: the device was designed using AutoCAD design suite as shown in Figure 2. A photograph of the constructed bike is shown in Figure 3.

2. Material Selection and acquisition: the device was made from cylindrical and rectangular metal pipes with diameters and thicknesses described above.

3. Material preparations: this involved cutting the metals into appropriate sizes for the different parts of the bike and drilling appropriate-sized holes especially for bolts and screws.

4. Welding: the welding method deployed for the project is the arc welding.

5. Attachment of accessories such as cable trigger, pedals, saddle, etc.

6. Finishing: the welded joints of the metal pieces were grinded using a grinding machine to a smooth finish and the whole piece was painted using a spray painting machine.

7. Testing/Evaluation: A functionality test as well as an ergonomic evaluation of the bike was carried out. The flowchart of the processes is presented in Figure 1.

\subsection{Evaluation}

The Bi-Modal Exercise Bike was evaluated for comfort, functionality and ergonomic suitability. The evaluation was performed in compliance with the guidelines by the health research ethics committee of the University of Lagos.

\subsubsection{Testing the comfort of the exercise bike}

The bike was carefully evaluated by ten (10) randomly selected subjects. The goal of the exercise was carefully explained to the sample subjects and an informed consent was obtained from each one. The subjects assessed the seat (saddle), the pedal, the frame, the handle bar and general ease of use and completed questionnaires accordingly. In each case, the participants were required to give their judgement of 
each of the components of the bicycle as listed, and their responses are as presented in Table 1.

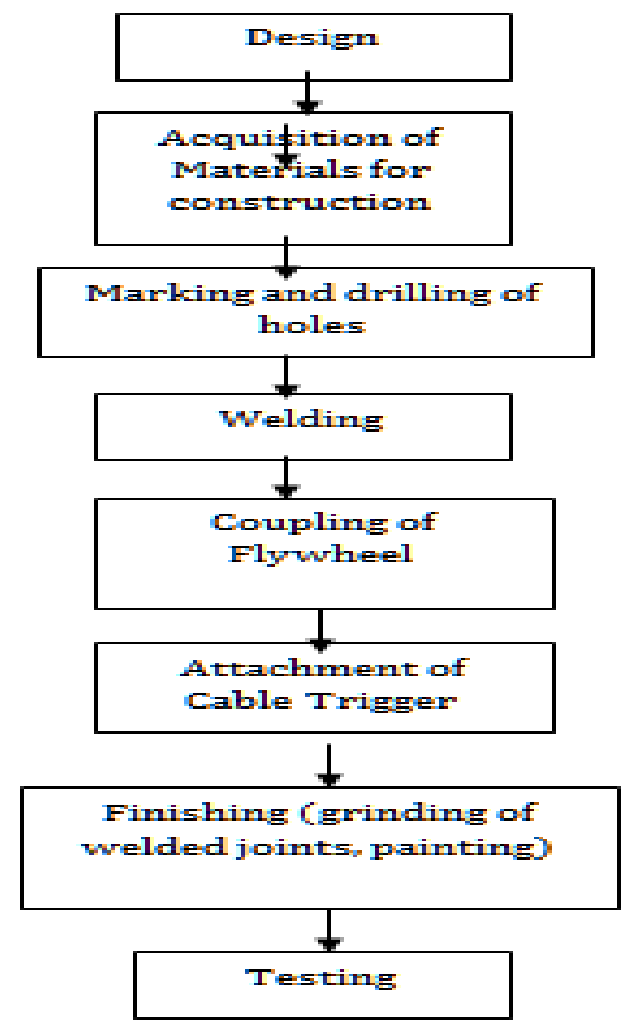

\subsubsection{Testing with heart rates of subjects}

According to the National Emergency Medicine Association, the heart rate is the number of times your heart beats per minute [19]. It may be obtained using a heart rate monitor or simply by placing the index and middle fingers together on the opposite wrist, about $1 / 2$ inch on the inside of the joint, in line with the index finger. The heart rates of the subjects were obtained before and after cycling on the exercise bicycle. The prototype testing of the bicycle ergometer was carried out using the following guidelines:

1. The heart rates of the participants were measured and recorded using a heart rate monitor.

2. Each participant was then required to perform some cycling on the exercise bicycle at a preferred load limit and to exhaustion.

3. The exercise was performed at $80 \mathrm{bpm}$ (beats per minute). The rate of cycling was determined using a metronome.

4. The heart rates were again measured immediately after the cycling period and recorded.

The above procedure was performed with each of the study participants and repeated after two days.

Figure 1: flowchart showing the construction processes for the bi-modal exercise bike

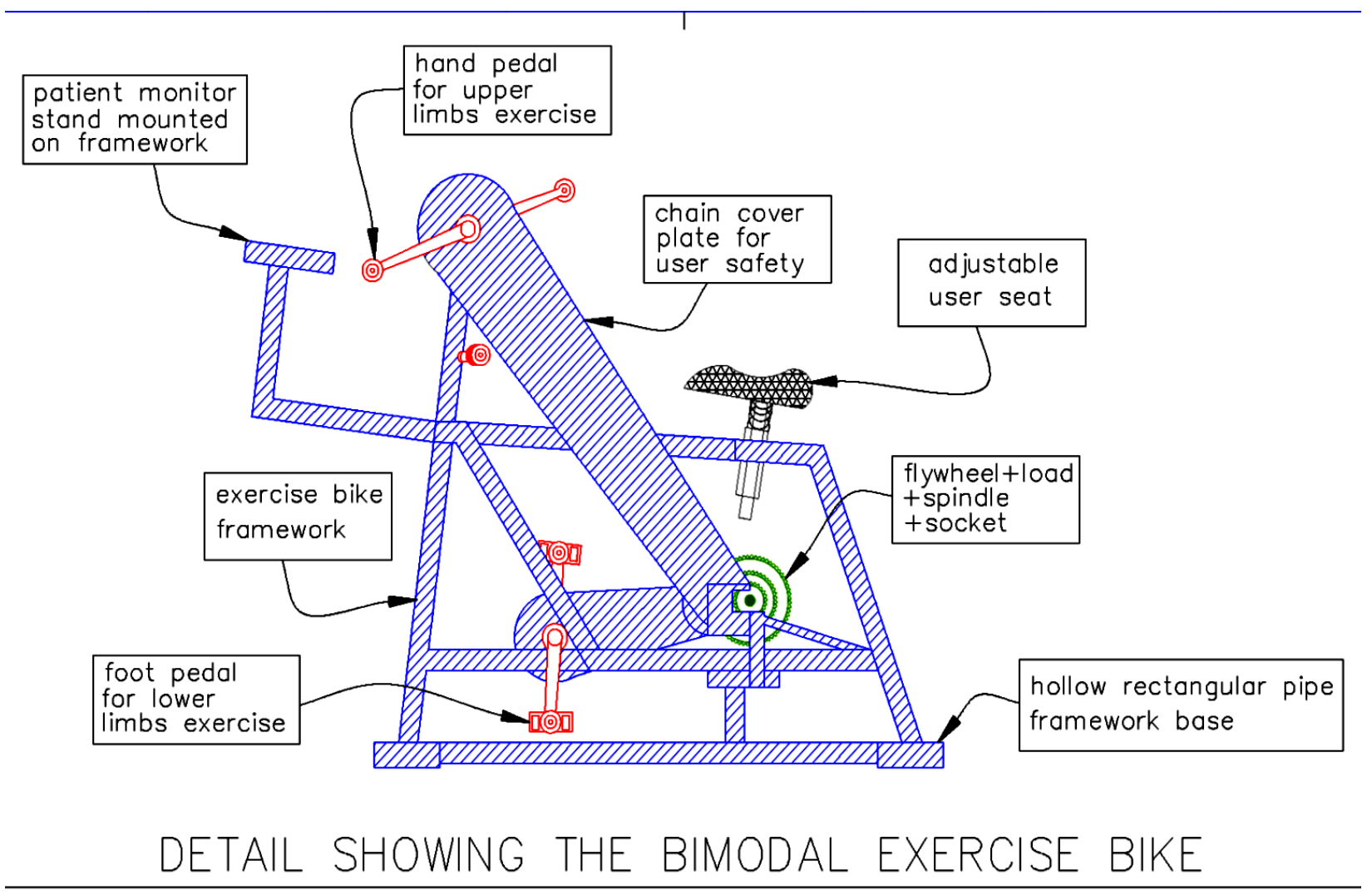

Figure 2: Side view of the bi-modal exercise bike design. 


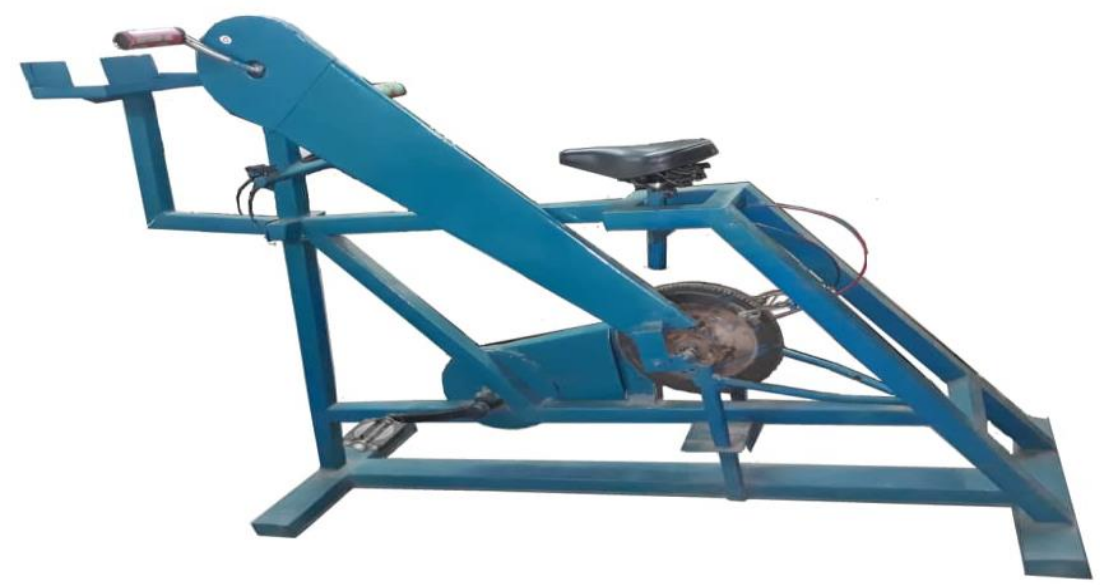

Figure 3: photograph of the side view of bi-modal exercise bike

\subsubsection{Ergonomic evaluation of the bike}

One hundred (65 males and 35 females) randomly selected persons, aged between 21-35 years, participated in the ergonomic evaluation. The anthropometric measures of the participants were taken (while they were in a sitting position) with the aid of an anthropometer. The knee height, popliteal height, buttock-popliteal length, buttock-knee height, thigh clearance, forward reach (sitting), and stature of the participants were determined. The anthropometric dimensions are as defined by ISO 7250 (1996) and reported in literature $[20,21]$. The results are shown in Table 6.

\section{RESULTS}

Table 2 shows the heart rates of the test subjects before and after cycling. The means and standard deviations of subject's heart rate (HR) are presented in Tables 3 and 4.

\subsection{Result of functionality test}

A test-retest reliability method was adopted for the heart rate test and a correlation was calculated using the IBM Statistical Package for Social Sciences, SPSS, version 21. A Pearson correlation coefficient was calculated for the relationship between the changed score of heart rate values of the first and second tests. A strong, positive correlation was found with correlation coefficient $\mathrm{r}=0.962$ at the level of significance $p<$ 0.001 , indicating a linear relationship between the two variables. The correlation result is shown in table 5 .

\subsection{Feedback from Users' assessment}

The feedback from users who assessed the bike in an evaluation is shown in Table 1.

\subsection{Ergonomic Evaluation}

The result of the anthropometric measures of the study participants used for the ergonomic evaluation of the bike is shown in Table 6. To assess the ergonomic suitability of the bike, the knee height of the participants were compared with the seat-pedal height. Accordingly, the buttock-popliteal length as well as the thigh clearance was compared with the seat-handle post length and the forward reach (while sitting) was compared with the seat-handle bar length of the bike. The dimensions of the bike which were used for the ergonomic evaluation are shown in Table 7.

Table 1: Feedback from users of the bi-modal exercise bicycle

\begin{tabular}{clllll}
\hline Subjects & Seat & Pedal & Frame & Handle Bar & Ease of Use \\
\hline 1 & Very Good & Good & Comfortable & Comfortable & Comfortable \\
2 & Very Good & Good & Comfortable & Excellent & Very Good \\
3 & Very Good & Good & Very Good & Excellent & Very Good \\
4 & Good & Good & Very Good & Excellent & Very Good \\
5 & Very Good & Good & Very Good & Excellent & Comfortable \\
6 & Good & Good & Very Good & Comfortable & Comfortable \\
7 & Very Good & Good & Very Good & Excellent & Very Good \\
8 & Very Good & Good & Very Good & Comfortable & Very Good \\
9 & Very Good & Good & Comfortable & Comfortable & Very Good \\
10 & Good & Good & Very Good & Excellent & Comfortable \\
\hline
\end{tabular}


Table 2: Results of heart rate measurements before and after cycling

\begin{tabular}{ccccccc}
\hline Subjects & $\begin{array}{l}\text { Heart rate } \\
\text { before } \\
\text { exercise }\end{array}$ & $\begin{array}{l}\text { Heart rate } \\
\text { after exercise }\end{array}$ & Deviation & $\begin{array}{l}\text { Heart rate } \\
\text { before } \\
\text { exercise }(2 \\
\text { days later })\end{array}$ & $\begin{array}{l}\text { Heart rate } \\
\text { after exercise } \\
\text { (2 days later) }\end{array}$ & Deviation \\
\hline 1 & 73 & 90 & 17 & 71 & 92 & 21 \\
2 & 70 & 88 & 18 & 72 & 88 & 16 \\
3 & 72 & 86 & 14 & 73 & 88 & 16 \\
4 & 72 & 88 & 16 & 73 & 90 & 17 \\
5 & 76 & 106 & 30 & 74 & 106 & 32 \\
6 & 74 & 94 & 20 & 74 & 94 & 20 \\
7 & 72 & 102 & 30 & 72 & 102 & 30 \\
8 & 76 & 108 & 32 & 76 & 106 & 30 \\
9 & 72 & 98 & 26 & 71 & 98 & 27 \\
10 & 73 & 102 & 29 & 72 & 100 & 28 \\
\hline
\end{tabular}

Table 3: Mean and SD of changed score values for the first and second heart rate tests $(N=10)$

\begin{tabular}{|c|c|c|c|c|}
\hline Variable & \multicolumn{4}{|c|}{$\mathrm{X} \pm \mathrm{SD}$} \\
\hline Heart rate (heats/min) & Pre-test (Day 1) & Post-test (Day 1) & Pre-test (after 2 days) & Post-test (after 2 days) \\
\hline & $73.00 \pm 1.89$ & $96.20 \pm 8.08$ & $72.70 \pm 1.57$ & $96.40 \pm 6.98$ \\
\hline
\end{tabular}

Table 4: Mean and SD values for the first and second heart rate tests $(N=10)$

\begin{tabular}{ccc}
\hline \multirow{2}{*}{ Variable } & \multicolumn{2}{c}{ Deviations $\mathrm{X} \pm$ SD } \\
\cline { 2 - 3 } & First-test & Second-test (After 2Days) \\
\hline Heart rate (beats $/ \mathrm{min})$ & $23.20 \pm 6.86$ & $23.70 \pm 6.34$ \\
\hline
\end{tabular}

Table 5: Correlation between pre-test and post-test heart rate $(H R),(N=10)$.

\begin{tabular}{|c|c|c|c|}
\hline & & First test & Second test \\
\hline \multirow{3}{*}{ First test } & Pearson Correlation & 1 & .962 \\
\hline & Sig. (2-tailed) & & .000 \\
\hline & $\mathrm{N}$ & 10 & 10 \\
\hline \multirow{3}{*}{ Second test } & Pearson Correlation & .962 & 1 \\
\hline & Sig. (2-tailed) & .000 & \\
\hline & $\mathrm{N}$ & 10 & 10 \\
\hline
\end{tabular}

Correlation is significant at the 0.01 level (2-tailed); $P<0.001 ; r=0.962$

Table 6: Anthropometric measures of study participants

\begin{tabular}{|c|c|c|c|c|c|c|c|}
\hline $\begin{array}{l}\text { Anthropometric } \\
\text { measure }\end{array}$ & Min & $\operatorname{Max}$ & $M e a n \pm S D$ & $\begin{array}{l}\text { Standard } \\
\text { error of } \\
\text { mean }\end{array}$ & $\begin{array}{l}5^{\text {th }} \\
\text { percentile }\end{array}$ & $\begin{array}{l}50^{\text {th }} \\
\text { percentile }\end{array}$ & $\begin{array}{l}95^{\text {th }} \\
\text { percentile }\end{array}$ \\
\hline Knee height & 53.00 & 69.00 & $57.82 \pm 2.65$ & 0.26 & 54.50 & 57.50 & 61.00 \\
\hline Popliteal height & 37.00 & 55.00 & $45.30 \pm 2.88$ & 0.29 & 41.00 & 45.00 & 49.00 \\
\hline $\begin{array}{l}\text { Buttock- } \\
\text { popliteal length }\end{array}$ & 41.50 & 59.00 & $49.16 \pm 3.32$ & 0.33 & 44.03 & 48.50 & 54.45 \\
\hline $\begin{array}{l}\text { Buttock-knee } \\
\text { length }\end{array}$ & 49.50 & 67.00 & $57.16 \pm 3.32$ & 0.33 & 52.03 & 56.50 & 64.00 \\
\hline Thigh clearance & 9.50 & 18.00 & $13.30 \pm 1.90$ & 0.19 & 10.00 & 14.00 & 15.18 \\
\hline $\begin{array}{l}\text { Forward reach } \\
\text { (sitting) }\end{array}$ & 68.00 & 97.00 & $76.89 \pm 6.12$ & 0.61 & 68.05 & 75.00 & 86.00 \\
\hline $\begin{array}{l}\text { Knee height }+ \\
\text { thigh clearance }\end{array}$ & 64.00 & 81.00 & $71.12 \pm 3.47$ & 0.35 & 66.50 & 70.50 & 76.00 \\
\hline Stature & 165.00 & 175.00 & $174.77 \pm 6.28$ & 0.63 & 165.00 & 175.00 & 182.00 \\
\hline
\end{tabular}

All dimensions are in centimetres $(\mathrm{cm})$. 
Table 7: Bike dimensions for ergonomic evaluation

\begin{tabular}{lccc}
\hline $\begin{array}{l}\text { Bicycle dimensions } \\
\text { required for ergonomic } \\
\text { evaluation }\end{array}$ & Seat-pedal height & Seat-handle post length & Seat- handle bar length \\
\cline { 2 - 4 } & $\begin{array}{l}\text { Min }=54.5 \mathrm{~cm} \\
\text { Max }=80.0 \mathrm{~cm}\end{array}$ & $70.0 \mathrm{~cm}$ & $70.0 \mathrm{~cm}$ \\
\hline
\end{tabular}

The bike was designed for an adjustable range of knee height; therefore, the seat-pedal height is a range between $54.5 \mathrm{~cm}$ and $80.0 \mathrm{~cm}$. This is to accommodate users of different heights and thus, different knee heights.

\subsubsection{Knee height and seat-pedal height}

The mean height of all the participants in the study is $57.82 \mathrm{~cm}$ as shown in Table 6. This value is well between the minimum and maximum values of the seat-pedal height. However, when a one-by-one comparison of the knee heights of all participants in the study was performed, the result is a $98 \%$ ergonomic suitability; with only two of the participants slightly falling outside of the range. Their knee heights were $54.3 \mathrm{~cm}$ and $54 \mathrm{~cm}$.

\subsubsection{Buttock-knee length and seat-handle post length}

This evaluation is necessary to ensure that the user can comfortably use the bike without the risk of sustaining and injury resulting from hitting their knee against the handle post/handle bar. The buttock-knee length is better suited for this purpose than the buttockpopliteal depth which is often used to establish the suitability of a seat. The mean buttock-knee length of the study population is $57.1 \mathrm{~cm}$. All one hundred participants in the study have their buttock-knee length less than the seat-handle post length, giving a $100 \%$ ergonomic suitability.

\subsubsection{Forward reach (sitting) and seat-handlebar length}

The forward reach (sitting) was used to evaluate the suitability of the handle bar length from a user's sitting position on the bike as well as the suitability of the arm pedals. The seat-handlebar and seat-arm pedal length was measured as $70 \mathrm{~cm}$. The mean forward reach (sitting) of the study participants was found to be $76.89 \mathrm{~cm}$. This value is approximately $7.0 \mathrm{~cm}$ higher than the seat-handlebar and seat-arm pedal length. A user is therefore required to bend the trunk slightly forward to attain a correct biking posture for improving the optimization between force and endurance in pedalling [22].

\section{DISCUSSIONS}

The seat (saddle) was designed for an adjustable range of users' heights. From the questionnaires completed by the test users, all testers considered the seat either good or very good. The pedals were also positioned at an adjustable distance from the seat to suit users of different heights. The handle bars have cushion attached to them to prevent any kind of abrasion to the hands of the user during cycling. In general, all testers considered the exercise bicycle comfortable or very good with respect to the ease of use. The results of the performance and ergonomic evaluation carried out on the bicycle ergometer shows that the design is both reliable and valid and can therefore be recommended for use for fitness training and for rehabilitation.

\section{CONCLUSION}

The design and fabrication of a simple bicycle ergometer using locally available materials shows that some medical equipment can be locally manufactured and/or assembled. This realization thus has professional advantage for the Biomedical Engineers and economic benefit to Nigeria. The essence of the study which is to make available a bi-modal exercise bicycle was also accomplished. It is believed that the full commercialization of this idea will reduce the cost of buying separately, an arm and a leg ergometer, as both devices have been incorporated into one. In addition, people who may be recovering from stroke can use the device for rehabilitation irrespective of which limbs may be affected.

\section{CONFLICT OF INTEREST}

No conflict of interest exists among the authors (and/or with any organisation) with respect to this exercise bike and the publication of this article.

\section{FUNDING}

No funding was received from any donor organization for carrying out this study.

\section{ACKNOWLEDGEMENT}

The authors wish to acknowledge Mr. Uche David for his contribution to the study.

\section{REFERENCES}

[1] Pate, R. R., Pratt, M., Blair, S. N., Haskell, W. L., Macera, C. A., Bouchard, C. "Physical activity and public health: A recommendation from the centers for Disease Control and Prevention and 
the American College of Sports Medicine", JAMA, Vol. 273, 402-407, 1995.

[2] Graham, I., Atar, D., Borch-Johnsen, K. “European guidelines on cardiovascular disease prevention in clinical practice: executive summary", European Heart Journal, Vol. 28, No. 19, pp. 2375-2414, 2007.

[3] Kim D., Lee H., Lee B., Kim J., Jeon J. "Effects of a Six-week Indoor Handbike Exercise Program on Health and Fitness Levels in People with Spinal Cord Injury: A Randomized Controlled Trial Study", Archives of Physical Medicine And Rehabilitation. 2015, pp. 1-28. doi:10.1016/j.apmr.07.010, 2015.

[4] Jeon J., Weiss C., Steadward R. "Improved glucose tolerance and insulin sensitivity after electrical stimulation-assisted cycling in people with spinal cord injury" Spinal Cord., Vol. 40, pp. 110-7, 2002.

[5] Keyser R. E., Rasch E. K., Finley M. "Improved upper-body endurance following a 12-week home exercise program for manual wheelchair users", Journal of Rehabilitation Research and Development, Vol. 40, pp. 501-10, 2003.

[6] Fetzner, M. G. and Asmundson, J. G. "Aerobic Exercise Reduces Symptoms of Posttraumatic Stress Disorder: A Randomized Controlled Trial", Cognitive Behaviour Therapy 2014. DOI: 10.1080/16506073.916745.2014.

[7] Ross K.J. and Wilson W. Anatomy and Physiology in Health and Illness. Seventh edition. Churchill (Livingstone) \& Robert Stevenson House, New York, 1990.

[8] Marieb N. E. Anatomy and Physiology Colouring: A complete Study Guide. Fourth Edition. The Benjamin/Cummings, New York, 2003.

[9] Kincaid H.N. "Use It or Lose It: A Study of Exercise and the Cardiovascular System" Retrieved from: http://hdl.handle.net/10150/ 613161 Accessed on April, 262018.

[10] Robergs R. A. and Keteyian S.J. Fundamentals of Exercise physiology for Fitness, Performance and health. Second edition. McGraw Hill, New York, 2003.

[11] Raasch C. C., Zajac F.E. "Locomotor strategy for pedaling: muscle groups and biomechanical functions" J. Neurophysiol, Vol. 82, pp. 515-525, 1999.

[12] Mazzocchio R, Meunier S, Ferrante S. "Cycling, a tool for locomotor recovery after motor lesions", Neuro. Rehabilitation, Vol. 23, pp. 67-80, 2008.
[13] Barbosa D. C., Santos P. Martins M. "The Application of Cycling and Cycling Combined with Feedback in the Rehabilitation of Stroke Patients: A Review", Journal of Stroke and Cerebrovascular Diseases Vol. 24, Number 2, pp. 253-273, 2015.

[14] Brown D. A., Nagpal S., Chi S. "Limb-loaded cycling program for locomotor intervention following stroke", Phys. Ther., Vol. 85, pp. 159168, 2005.

[15] Chang M.L., Shih C.H. and Lin Y.C. "Encouraging obese students with intellectual disabilities to engage in pedalling an exercise bike by using an air mouse combined with preferred environmental stimulation", Research in Developmental Disabilities Vol. 35, pp. 32923298, 2014.

[16] Lin S. I., Lo C. C., Lin P. Y., "Biomechanical assessments of the effect of visual feedback on cycling for patients with stroke", J. Electromyogr. Kinesiol., Vol. 22, pp. 582-588, 2012.

[17] Potempa K, Lopez M, Braun L. T., "Physiological outcomes of aerobic exercise training in hemiparetic stroke patients" Stroke, Vol. 26, pp. 101-105, 1995.

[18] Kautz S.A. and Brown D. A. "Relationships between timing of muscle excitation and impaired motor performance during cyclical lower extremity movement in post-stroke hemiplegia" Brain Vol. 121 (Pt 3), pp. 515-526. 1998.

[19] NEMA (National Emergency Medicine Association) "Heart rate or pulse rate: what you should know about your heart rate or pulse rate" Retrieved from: https://www.nemahealth.org index.php/heart-rate-or-pulse-2 Assessed on May 17, 2018.

[20] Pheasant S. Bodyspace: Anthropometry, Ergonomics and the design of wok. Second edition. Taylor and Francis Publishers, London, 2003.

[21] Taifa I. W. and Desai D. A. "Anthropometric measurements for ergonomic design of students' furniture in India". Engineering Science and Technology, an International Journal. Vol. 20, pp. 232-239, 2017.

[22] Fridegotto M. "Posture and muscular imbalances: Pilates as a complementary practice for cycling" Retrieved from: https://www.basipilates.com/ media/paper/posture-and-muscularimbalances-in-cyclist.pdf Assessed on May 18, 2018. 